\title{
Leukapheresis and Hyperleukocytosis, Past and Future
}

\section{Dongdong Zhang (ID) \\ Yufan Zhu ${ }^{2}$ \\ Yanxia Jin ${ }^{3}$ \\ Natasha Mupeta Kaweme iD ${ }^{3}$ \\ Youhong Dong' \\ 'Department of Oncology, Xiangyang} No. I People's Hospital, Hubei University of Medicine, Xiangyang, Hubei, 441000, People's Republic of China; ${ }^{2}$ Orthopedics department, Zhongnan Hospital, Wuhan University, Wuhan, People's Republic of China; ${ }^{3}$ Department of Hematology, Zhongnan Hospital, Wuhan University, Wuhan, People's Republic of China
Correspondence: Youhong Dong Department of Oncology, Xiangyang No. I People's Hospital, Hubei University of Medicine, Xiangyang, Hubei, 441000, People's Republic of China Email dongyouhong2005@163.com

\begin{abstract}
Hyperleukocytosis is a hematologic crisis caused by excessive proliferation of leukemic cells and has a relatively high early mortality due to a series of severe complications. Therefore, prompt and effective intervention is required. Leukapheresis performed using apheresis equipment to separate leukocytes from peripheral blood, at the same time returns autologous plasma, platelets and erythrocytes to the patient, is applied clinically for the treatment of hyperleukocytosis. Leukapheresis not only removes excessive leukocytes rapidly and corrects metabolic abnormalities but also alleviates the symptoms of leukostasis. In addition, the procedure of leukapheresis is generally well tolerated. Leukapheresis has become one of the most imperative adjuvant therapies to treat hyperleukocytosis, especially in the patient who was not inappropriate to cytoreduce with Ara-C or hydroxyurea. In this review, we present the background of leukapheresis development and highlight its clinical application in hyperleukocytic leukemia patients.
\end{abstract}

Keywords: hyperleukocytosis, leukapheresis, leukostasis, hyperleukocytic leukemia

\section{Introduction}

Apheresis is a procedure referred to as the separation and retention of one or more components of blood while returning the remaining components to the patient. Apheresis can be divided into leukapheresis, therapeutic plasma exchange, extracorporeal photopheresis, thrombocytapheresis and erythrocytapheresis. ${ }^{1}$ So far, the process of apheresis is applied in the collection of peripheral blood stem cells or granulocyte concentrates. Leukapheresis is a type of apheresis used for the withdrawal of leukocytes and the re-infusion of leukocyte-poor plasma. It has clinical significance in the treatment of hematological diseases and provides an alternative strategy in managing active inflammatory bowel disease (IBD). ${ }^{2}$

Hyperleukocytosis is usually defined as peripheral blood leukocyte count exceeding $100 \times 10^{9} / \mathrm{L}$. Hyperleukocytosis is frequently observed in acute lymphoblastic leukemia (ALL) with an incidence range of 10 30\%, the second being acute myeloid leukemia (AML). It can also be observed in some patients with chronic myeloid leukemia $(\mathrm{CML})^{3}$ and chronic myelomonocytic leukemia (CMML). ${ }^{4,5}$ Despite its strict definitive criteria, some types of leukemia can also cause hyperleukocytosis-related complications when the leukocyte count is below this level. ${ }^{6}$ For instance, when peripheral blood leukocyte count exceeds $50 \times 10^{9} / \mathrm{L}$, symptoms of leukostasis may appear in a patient with AML but may remain asymptomatic in patients with ALL even with a leukocyte count higher than $50 \times 10^{9} / \mathrm{L}$.

Due to the delayed diagnosis of hyperleukocytosis, there is an increased rate in mortalities of $40 \%$ per week. ${ }^{7}$ In a systematic review to determine if leukapheresis 
and low-dose chemotherapy reduced the incidence of early mortality, Oberoi et al highlight that the most common cause of early mortality is hemorrhage, followed by leukostasis, sepsis, respiratory failure and renal failure. ${ }^{8}$ From recent studies, it can be concluded that hyperleukocytosis is a clinical emergency that needs prompt diagnosis and initiation of treatment. At present, the commonly used treatments for hyperleukocytosis include cytoreductive therapy, leukapheresis, low-dose cytarabine chemotherapy, and hydroxyurea.

\section{Leukapheresis}

Leukapheresis is a procedure carried out to isolate leukocytes from peripheral blood. The manufacture and improvement of leukapheresis equipment have undergone countless attempts by scientists (Figure 1). Currently, leukapheresis is commonly used for the treatment of various diseases, it is also used for diagnostic purpose as it can increase circulating tumor cells yields. ${ }^{9,10}$

\section{The Development History of Leukapheresis Apparatus}

Apheresis, a vital technique or useful separation method used by several laboratories and in clinical practice to separate blood into red blood cells, white blood cells, platelets, and non-cell plasma. ${ }^{11}$ The first apparatus was designed in 1949 for this purpose and was a kind of falling film centrifuge that depended on the differential densities. ${ }^{12}$ Unfortunately, this centrifuge could only separate leukocytes and platelets in vitro; therefore, it has not been directly applied in living organisms.

The Cohn ADL centrifuge was later developed in 1956 as a simplified centrifuge for the separation and processing of all types of cells without producing rouleaux-reagents. It was the first centrifuge to provide a continuous flow washing solution to counteract bacterial contamination.
Conversely, its complexity and cost hinder its extensive and conventional application. ${ }^{13}$ In the same year, 1956, Allan Latham modified the Cohn's centrifuge and designed a disposable plastic bowl which was called "Latham Bowl". This enhanced apparatus reduced frictional heat and eliminated gravity drainage making it possible to interrupt an experimental or routine cell separation at any time. Both apparatuses designed could not separate the various cellular components in vivo.

To facilitate the procurement of separating leukocytes in a continuous flow centrifuge in vivo, the National Cancer Institute and the International Business Machines Corporation initiated a joint project in 1964 to develop a continuous flow centrifuge (NCI-IBM blood cell separator). In 1968, Buckner et al successfully separated dog blood cells using the NCI-IBM blood cell separator. Studies have shown that this method can collect a lot of blood sedimentation brown layer of cells, without causing significant damage to leukocytes, platelets, and erythrocytes. ${ }^{14}$ Although the number of collected granulocytes were few, it provided a new idea for the clinical application of blood separation techniques.

In 1970, Djerassi performed filtration leukapheresis (FL) by reversibly absorbing the nylon-wool filter to obtain large amounts of granulocytes for single donor blood transfusion. ${ }^{15}$ However, when the collected granulocytes were transfused, the posttransfusion increments were significantly lower than previously collected by different centrifugation methods. Herzig modified Djerassi's by using a peristaltic pump to incorporate the safety feature of continuous-low blood cell separator in $1972 .{ }^{16}$ Because granulocytes make up only a small part of whole blood and its density overlaps with that of erythrocytes, so the collected granulocytes were often contaminated by erythrocytes. ${ }^{17}$ This new FL technique did not solve the problem of complete separation of blood cells.

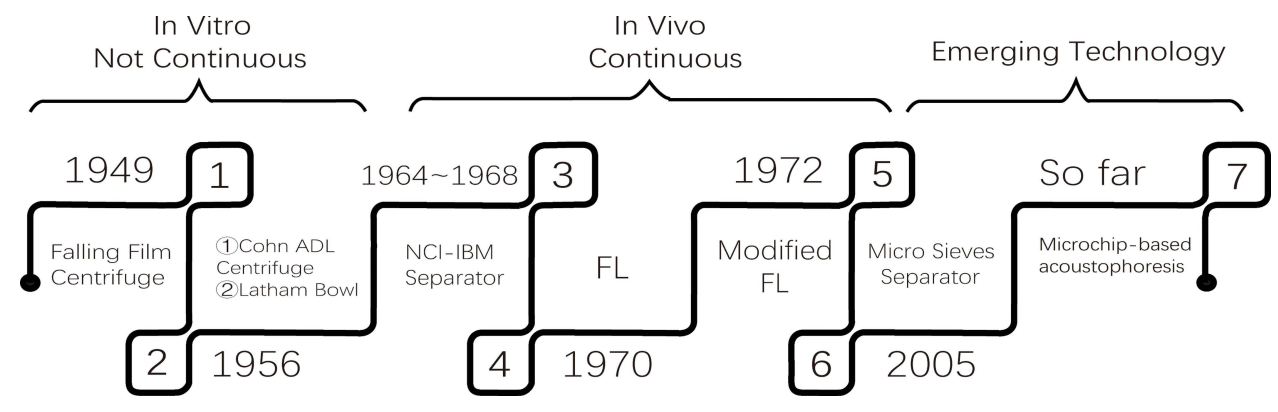

Figure I The emergence of different blood cell separators at different periods.

Abbreviations: NCl-IBM, the National Cancer Institute and the International Business Machines Corporation; FL, filtration leukapheresis. 
In 2005, Palaniappan invented a device employing micro sieves which made use of different cell size and shape to separate leukocytes. The sieve was designed to allow erythrocytes to pass through while providing a barrier for larger spherical white blood cells. ${ }^{18}$ The shortcoming is the higher the flow rate, the greater probability of contamination.

So far, the most widely used blood cell separators in hospitals are the SPECTRA OPTIA, Fresenius COM.TEC, Fenwal Amicus and Trima Accel. ${ }^{19}$ The principle of these machines depends on the gradient density difference between different cells. Platelets and erythrocytes often contaminate the collected leukocytes due to low density of blood components $(1.6 \%-2.2 \%)$, and ultimately results in the erythrocyte and platelet loss. ${ }^{20}$ In the past decades, more advanced technology was applied to the improvement of the apparatus. The acoustic separation technique can be used to separate blood samples using acoustic impedance. ${ }^{21}$ The novel microchip-based acoustophoresis technique can be more efficient to separate leukocytes ${ }^{22}$ and platelets $^{23}$ than the traditional apparatus in vitro, unfortunately, none of these devices have been adopted into clinical practice the past ten years, but may be promising techniques to improve current leukapheresis in future.

\section{The Operation Procedure of Leukapheresis}

Leukapheresis is performed by applying whole blood to a continuous flow of blood cell separator. Given the example of the 'blood cell separator Fresenius COM.TEC, generally, the autoMNC program is picked for leukapheresis. A rigid wall double lumen catheter is needed to ensure stable flow, the most frequently used site for venepuncture is the median cubital vein. The machine parameters used for leukapheresis are determined by the donor's sex, height, weight, hematocrit, and pre-apheresis peripheral blood leukocyte count. The detailed information is as follows: circulating blood volume is kept between 7.5 and $11.5 \mathrm{~L}$, processing time is maintained at 3 to 3.5 hours, the routine collect flow rate should be maintained at $35-45 \mathrm{~mL} / \mathrm{min}^{24}$ Whether additional leukapheresis procedures were needed depended on individual symptoms, peripheral WBC count and plan for chemotherapy. The anticoagulant citrate is used in case of coagulation during extracorporeal blood circulation. The ratio between citrate and whole blood is often 1:8-1:12. Before and during the
$1 / 3$ of the procedure, $10 \mathrm{~mL}$ of $10 \%$ calcium gluconate is given in case of hypocalcemia. ${ }^{25}$ All patients should take preoperative investigations, including routine blood tests, electrolytes, liver and kidney functions, and blood coagulation profile before leukapheresis. The risk of hemorrhage can be evaluated according to the test results. When results indicate $\mathrm{PLT}<30 \times 10^{9} / \mathrm{L}$ or $\mathrm{Hb}<70-80 \mathrm{~g} / \mathrm{L}$, preoperative blood transfusion must be considered. ${ }^{26}$ The patient's blood pressure, heart rate, $\mathrm{O}^{2}$ saturation and leukocyte count should be closely monitored during leukapheresis. Complete blood count test is highly recommended before the beginning of the procedure, at the midway point and at the ending of the procedure. ${ }^{27,28}$

\section{The Adverse Reactions of Leukapheresis Hypocalcemia}

Hypocalcemia is a common adverse reaction. Anticoagulants like citrate are used to prevent clotting of the apheresis circuit during leukapheresis bind calcium leading to symptoms of hypocalcemia. This often occurs when circulating blood volume exceeds $1800 \mathrm{~mL}$ and patients present with a low blood calcium phenomenon: oral, face and limb numbness, chest pain, lightheadedness and nausea, prolonged QTc interval is infrequent. ${ }^{11}$ When this occurs, slowing down the flow rate of whole blood and timely supplementation with calcium simultaneously, usually alleviates symptoms within 10 minutes.

\section{Bleeding Risk}

Because of the extracorporeal circulation of components whole blood and the use of anticoagulants during leukapheresis, the risk of hemorrhage is increased. Therefore, when patients show a tendency of bleeding and platelets are less than $30 \times 10^{9} / \mathrm{L}$, preoperative plasma infusion is recommended to reduce the risk of hemorrhage.

\section{Low Blood Volume Reaction}

After a lengthy leukapheresis procedure, patients may present with symptoms of low blood volume such as dizziness, dryness of the mouth, irritability, reduced urine output, hypotension, and weak pulse due to loss of erythrocytes and platelets during the procedure. If any of these symptoms appear, vital signs should be immediately assessed and a determination of insufficiency of circulating blood volume made. Leukapheresis should be suspended if necessary. 


\section{Blood Loss}

Hyperleukocytic leukemia patients often presented with severe anemia. The expected blood loss not only occurs during the procedure but also because of the extracorporeal volume. Granulocyte density overlaps with that of erythrocytes which leads to the contamination of erythrocytes. Platelet loss is a similar concern. ${ }^{29}$ The application of a new type of blood cell separators may reduce the incidence of this complication.

\section{Allergic Reaction}

The incidence of this adverse reaction is low, often occurs during a blood transfusion. Patients often present with varying degrees of urticaria, itchiness, and other symptoms. Dexamethasone or antihistamines can be given in this condition, and if symptoms like dyspnea and fever appear, the procedure must be suspended.

\section{The Application of Leukapheresis}

Leukapheresis can be divided into diagnostic leukapheresis and therapeutic leukapheresis according to its purpose. The diagnostic leukapheresis was brought forward in recent years and is used to effectively collect circulating tumor cells $(\mathrm{CTCs})^{30}$ which are a promising biomarker for the diagnosis and treatment of various systemic cancers. ${ }^{10}$ The therapeutic leukapheresis is widely used in clinicians and this paper puts an emphasis on it.

The American Society for Apheresis (ASFA) reached the latest consensus on the therapeutic apheresis in 2019, as summarized in Table 1. ${ }^{31}$ The guidelines recommend therapeutic leukapheresis as the second-line therapy for the treatment of hyperleukocytosis with complications of leukostasis, as adjunctive therapy to chemotherapy. Another emerging use is in the treatment of IBD. A novel leukapheresis column can selectively remove the production of inflammatory cytokines which significantly improves IBD patient symptoms and reduces the need for drugs for a more extended period after leukapheresis. ${ }^{32,33}$
The optimum role of therapeutic leukapheresis in the treatment of IBD is not well established according to the guidelines, so whether leukapheresis should be used or not should be individualized. Inclusion body myositis and dermatomyositis or polymyositis were not recommended in the 2019 ASFA Guidelines compared to the 2013 and 2016 ASFA Guidelines.

\section{The Application of Leukapheresis in Hyperleukocytosis}

Hyperleukocytosis is a medical emergency caused by an increased number of leukocytes sludging in capillaries. The recommended initial therapy is standard induction chemotherapy. Assessment for DIC or TLS must be done daily after chemotherapy because of increased lysis or bursting of blasts releasing contents into circulation. Supportive measures, such as the use of allopurinol or rasburicase and intravenous hydration, is recommended to reduce serum uric acid levels and ensure an adequate urine output. Leukapheresis can rapidly remove excessive leukocytes by blood cell separators and is a mechanical separation method that removes leukocytes from the body. In addition, it is effective as a single episode of leukapheresis can reduce leukocytes by $10 \%$ to $70 \%{ }^{27}$ It is typically used in patients with the symptoms of leukostasis that are intolerable to induction chemotherapy. ${ }^{26}$ The advantage and disadvantage of leukapheresis in the treatment of hyperleukocytosis are elaborated below (Table 2).

\section{Advantage}

Our previous study has shown that leukapheresis can rapidly reduce the number of leukocytes compared to chemotherapy. In this study, leukocytes were reduced significantly, and renal function improved significantly following leukapheresis. ${ }^{34}$ Leukapheresis can reduce leukocyte aggregation in the pulmonary and cerebral microcirculation by recruiting the marginal leukemic cells into the intravascular space, ${ }^{4}$ which involves

Table I Indication Categories for Therapeutic Leukapheresis

\begin{tabular}{|l|l|l|l|l|}
\hline Disease Name & Modality & Disease Condition & Treatment Status & Recommendation \\
\hline Hyperleukocytosis & Leukapheresis & Symptomatic & Second-line & Moderate \\
\cline { 3 - 6 } & & Prophylaxis or secondary & Individualization & Weak \\
\hline \multirow{2}{*}{ Inflammatory bowel disease } & \multirow{2}{*}{ Adsorptive cytapheresis } & Ulcerative colitis & Individualization & Strong \\
\cline { 3 - 6 } & & Crohn's disease & Individualization & Weak \\
\hline
\end{tabular}


Table 2 The Pros and Cons of Leukapheresis

\begin{tabular}{|c|c|c|c|}
\hline Author and Year & Advantage & Disadvantage & Perspectives \\
\hline $\begin{array}{l}\text { Powell et al } \\
(1991)^{35}\end{array}$ & $\begin{array}{l}\text { Leukapheresis could modulate the cell } \\
\text { cycle distribution and increase the } \\
\text { fraction of leukemia cells in S-phase. }\end{array}$ & NA & $\begin{array}{l}\text { Leukapheresis may increase the } \\
\text { efficiency of cytarabine and other } \\
\text { S-phase specific agents. }\end{array}$ \\
\hline $\begin{array}{l}\text { Galera et al } \\
(2016)^{39}\end{array}$ & $\begin{array}{l}\text { Leukapheresis could improve } \\
\text { pulmonary leukostasis in pregnant } \\
\text { woman without side effect. }\end{array}$ & NA & $\begin{array}{l}\text { Leukapheresis was recommended for } \\
\text { the treatment of hyperleukocytosis } \\
\text { with neurologic and pulmonary } \\
\text { manifestation by ASFA as it could } \\
\text { reduce the intravascular leukemic } \\
\text { cellular burden rapidly and improve } \\
\text { tissue perfusion. }\end{array}$ \\
\hline $\begin{array}{l}\text { Bruserud et al } \\
(2012)^{36}\end{array}$ & $\begin{array}{l}\text { Leukapheresis was a safe and effective } \\
\text { procedure for the treatment of } \\
\text { hyperleukocytic leukemia with life- } \\
\text { threatening complications and without } \\
\text { side effect. }\end{array}$ & NA & $\begin{array}{l}\text { Leukapheresis may have therapeutic } \\
\text { effect in hyperleukocytic leukemia } \\
\text { patients with leukostasis. The } \\
\text { important thing to note was } \\
\text { chemotherapy should not be } \\
\text { postponed for the prevention of the } \\
\text { rapid re-accumulation of blasts. }\end{array}$ \\
\hline $\begin{array}{l}\text { Sung et al }(2012)^{37} \\
\text { Jin et al }(2018)^{34}\end{array}$ & $\begin{array}{l}\text { Leukapheresis could reduce the } \\
\text { occurrence of renal failure and } \\
\text { metabolic derangements with little } \\
\text { toxicity on hepatic-renal function }\end{array}$ & NA & $\begin{array}{l}\text { Leukapheresis was safe and efficient in } \\
\text { leukoreduction and could be used for } \\
\text { the treatment of children and pregnant } \\
\text { women with hyperleukocytic leukemia. }\end{array}$ \\
\hline $\begin{array}{l}\text { Giammarco et al } \\
(2017)^{42}\end{array}$ & NA & $\begin{array}{l}\text { Leukapheresis required specialized } \\
\text { equipment and trained personnel. }\end{array}$ & $\begin{array}{l}\text { It may be challenging to perform } \\
\text { leukapheresis on large-scale. }\end{array}$ \\
\hline Allon et al $(2007)^{43}$ & NA & $\begin{array}{l}\text { Leukapheresis required a central } \\
\text { venous catheter which hold a high risk } \\
\text { of bleeding, thrombosis and catheter- } \\
\text { related infection and venous stenosis at } \\
\text { the catheter site. }\end{array}$ & $\begin{array}{l}\text { Patients who underwent the treatment } \\
\text { of leukapheresis need more intensive } \\
\text { care. }\end{array}$ \\
\hline $\begin{array}{l}\text { Punzel et al } \\
(2017)^{46}\end{array}$ & NA & $\begin{array}{l}\text { Leukapheresis can reduce the number } \\
\text { of leukocytes rapidly along with the } \\
\text { loss of red blood cell and platelet }\end{array}$ & $\begin{array}{l}\text { Patients who underwent leukapheresis } \\
\text { with hemoglobin below } 60 \mathrm{~g} / \mathrm{L} \text { or } \\
\text { platelet below } 30 \times 10^{9} / \mathrm{L} \text { need be pre- } \\
\text { treated with red blood cell or platelet } \\
\text { transfusion. }\end{array}$ \\
\hline Sanz et al $(2009)^{47}$ & NA & $\begin{array}{l}\text { leukapheresis may exacerbate } \\
\text { coagulopathy associate with a high risk } \\
\text { of death at induction. }\end{array}$ & $\begin{array}{l}\text { Leukapheresis was not recommended } \\
\text { for the treatment of acute } \\
\text { promyelocytic leukemia. }\end{array}$ \\
\hline
\end{tabular}

Abbreviation: NA, not available.

moving of leukocytes from the reserve pool into the circulation pool, and resting stage into the breeding period to increase the sensitivity of chemotherapy. Leukapheresis plays an essential role on bone marrow function, as it can arrest some bone marrow leukemic cells in synthesis-phase, thereby enhancing the sensitivity of cell-specific drugs such as Ara-C or other synthesis-phase specific agents. ${ }^{35}$
Leukocyte depletion induced by chemotherapy may cause some side effects. The short-term destruction of many leukocytes often induces tumor lysis syndrome, associated with hyperuricemia and electrolyte disturbance. Furthermore, the use of chemotherapeutic drugs causing cytotoxic effects. Leukapheresis can remove excessive leukocytes from the body rapidly without the abovementioned adverse events. ${ }^{36}$ A meta-analysis study 
reported that leukapheresis could decrease the occurrence of tumor lysis syndrome. ${ }^{8}$ One study from the "Children's Oncology Group" proved that it could reduce the occurrence of renal failure and metabolic derangements in children with hyperleukocytic leukemia. ${ }^{37}$ Moreover, leukapheresis was safe even in small children with lowbody weight. ${ }^{38}$ Our study also revealed that leukapheresis had little toxicity on hepatic-renal function compared to chemotherapy. ${ }^{34} \mathrm{~A}$ study indicated that leukapheresis could improve pulmonary leukostasis in a pregnant woman without side effect. ${ }^{39}$ Multiple case reports proposed leukapheresis for management of hyperleukocytosis in pregnant as leukapheresis had no adverse effect on the mother and fetus. ${ }^{40,41}$ Therefore, leukapheresis was safe and also could be used for the treatment of children (excluding acute promyelocytic leukemia) and pregnant women with hyperleukocytic leukemia.

\section{Disadvantage}

Leukapheresis requires specialized equipment and trained personnel. During leukapheresis, the patients' vital signs are monitored closely, of which some patients may need to be transferred to an intensive care unit (ICU). For critically ill patients, leukapheresis may need to be performed in the $\mathrm{ICU} ;{ }^{42}$ therefore, it may be challenging to perform this procedure on a large-scale due to its complexity and high cost.

Leukapheresis requires a central venous catheter placement because more than one procedure is required for weaker patients, which holds a high risk of bleeding and thrombosis at the catheter site. Adversely, the patient could develop a catheter-related infection and venous stenosis because of improper catheter care. ${ }^{43}$

During leukapheresis, to prevent coagulation and thrombosis in the extracorporeal circulation, anticoagulants are often used. Citrate is commonly used, and functions by binding calcium which leads to hypocalcemia. In view of preventing hypocalcemia, supplemental calcium is provided, but this can also lead to calcium-phosphate precipitation and worsen tumor lysis syndrome. ${ }^{44,45}$

Leukapheresis can reduce the number of leukocytes rapidly along with the loss of red blood cell and platelet, ${ }^{46}$ so it is not suitable for patients with hemoglobin below $60 \mathrm{~g} / \mathrm{L}$ or platelet below $30 \times 10^{9} / \mathrm{L}$; moreover, leukocytes can rebound after the completion of the procedure without subsequent treatment. Leukapheresis is not recommended in the initial treatment of acute promyelocytic leukemia (APL) with hyperleukocytosis. An expert panel reviewed this on behalf of the "European Leukemia Net", and the conclusion was due to the possibility that leukapheresis can exacerbate coagulopathy associate with a high risk of death at induction. ${ }^{47}$ Patients with hyperleukocytosis and comorbidities such as cardiovascular dysfunction, coagulation disorders, and severe hepatic and renal dysfunction, should be evaluated seriously to avoid extra-procedural risks. ${ }^{48}$

Generally, leukapheresis can decrease the leukocyte count rapidly to improve circulation and reduce the risk of TLS; these advantages outweigh the disadvantages as mentioned above. For this reason, hyperleukocytic leukemia patients can benefit from leukapheresis except in APL or severe contraindications. However, it is important to note that chemotherapy should not be postponed for the prevention of the rapid re-accumulation of blasts.

Hyperleukocytosis has a poor prognosis due to its early mortality and insensitivity to initial chemotherapy. ${ }^{48}$ Whether leukapheresis had an impact on early death rate and long-term survival was still controversial (Table 3). ${ }^{49-55}$ Bug compared patients with hyperleukocytic leukemia who received chemotherapy and leukapheresis respectively and found that leukapheresis can significantly improve survival in the first 3 weeks compared to chemotherapy. ${ }^{56}$ A retrospective study further revealed that leukapheresis could reduce the 2-week mortality rate in hyperleukocytosis patients, but there was no effect on longterm survival. ${ }^{51}$ Pastore et al found that prophylactic leukapheresis did not reduce early mortality within seven days in hyperleukocytosis patients with or without leukostasis. ${ }^{57}$ Recently, a large retrospective and multicenter study showed leukapheresis had no significant improvement on the 30-day mortality and overall survival (OS) in hyperleukocytic AML. ${ }^{58}$ Due to the different general conditions, disease classifications, treatment protocols, and patients selected in different studies, whether leukapheresis had an impact on early death rate and OS is still controversial. ${ }^{59}$

\section{Conclusion}

Leukemia patients often present with severe anemia and thrombocytopenia. ${ }^{60,61}$. The leukapheresis apparatus currently used in clinical practice can trigger rapid erythrocyte and platelet loss which may increase the risk of hemorrhage, aggravate anemia and affect the efficiency of subsequent chemotherapy. Because the current leukocyte depletion method requires increased systemic blood 
Table 3 A Summary of Clinical Studies of Leukapheresis in Patients with Hyperleukocytic Leukemia

\begin{tabular}{|c|c|c|c|c|}
\hline $\begin{array}{l}\text { Author } \\
\text { and Year }\end{array}$ & Patients & $\begin{array}{l}\text { Leukoreduction } \\
\text { Rate }\end{array}$ & Study Summary & $P$ value \\
\hline $\begin{array}{l}\text { Porcu et al } \\
(1997)^{49}\end{array}$ & 48 & $>50 \%$ & $\begin{array}{l}\text { Leukapheresis could not improve one-week mortality in patients with } \\
\text { hyperleukocytic leukemia, especially these presented with renal, neurological and } \\
\text { respiratory complications. }\end{array}$ & $>0.200$ \\
\hline $\begin{array}{l}\text { Thiebaut } \\
\text { et al } \\
(2000)^{50}\end{array}$ & 53 & $\begin{array}{l}\text { Median was } 50 \% \\
\text { (range } 0 \text { to } 91 \text { ) }\end{array}$ & Patients with hyperleukocytic leukemia may benefit from initial leukapheresis. & NA \\
\hline $\begin{array}{l}\text { Giles et al } \\
(2001)^{51}\end{array}$ & 71 & $\begin{array}{l}\text { Median was nearly } \\
57 \%(66.4 / 116.5)\end{array}$ & $\begin{array}{l}\text { Leukapheresis could reduce two-week mortality and achieved a higher complete } \\
\text { remission rate compared to control group. }\end{array}$ & 0.060 \\
\hline $\begin{array}{l}\text { Chang et al } \\
(2007)^{52}\end{array}$ & 22 & Not shown & $\begin{array}{l}\text { Leukapheresis could not improve early mortality, on the contrary, may be } \\
\text { detrimental. }\end{array}$ & 0.367 \\
\hline $\begin{array}{l}\text { Bug et al } \\
(2007)^{56}\end{array}$ & 25 & Median was $47 \%$ & $\begin{array}{l}\text { Leukapheresis could reduce the risk of early death by Day- } 2 \text { I, but had no impact on } \\
\text { overall survival. }\end{array}$ & 0.015 \\
\hline $\begin{array}{l}\text { Oberoi et al } \\
(2014)^{8}\end{array}$ & 1354 & Not shown & $\begin{array}{l}\text { Leukapheresis did not reduce early mortality in patients with hyperleukocytic } \\
\text { leukemia. }\end{array}$ & 0.670 \\
\hline $\begin{array}{l}\text { Wong et al } \\
(2015)^{55}\end{array}$ & 31 & $\begin{array}{l}\text { Median was nearly } \\
69 \%\end{array}$ & Leukapheresis could not improve 30-day mortality and overall survival. & 0.250 \\
\hline $\begin{array}{l}\text { Nan et al } \\
(2017)^{54}\end{array}$ & 26 & $\begin{array}{l}\text { Median was } 55 \% \\
\text { (rangel9 to } 94)\end{array}$ & $\begin{array}{l}\text { Leukapheresis was associated with significantly lower } 28 \text {-day mortality rate } \\
\text { compared to control group. }\end{array}$ & 0.022 \\
\hline $\begin{array}{l}\text { Choi et al } \\
(2018)^{53}\end{array}$ & 59 & $\begin{array}{l}\text { Median was nearly } \\
59 \%(119 / 202)\end{array}$ & $\begin{array}{l}\text { There was not enough evidence to show that leukapheresis had a positive effect on } \\
\text { survival outcome and incidence of early complications. }\end{array}$ & $\begin{array}{l}\text { AML: } \\
0.846 \\
\text { ALL: } \\
0.822\end{array}$ \\
\hline $\begin{array}{l}\text { Stahl et al } \\
(2020)^{58}\end{array}$ & 113 & Not shown & $\begin{array}{l}\text { Leukapheresis had no impact on 30-day mortality, achievement of complete } \\
\text { remission, or overall survival. }\end{array}$ & 0.329 \\
\hline
\end{tabular}

Abbreviation: NA, not available.

circulation and takes a longer time, therefore, it is difficult for some patients to tolerate. Further improvements of leukapheresis apparatus to achieve rapid and accurate sorting of leukocytes and minimizing the possible adverse reactions during the procedure are the problems that need to be solved urgently.

Hyperleukocytosis has a poor prognosis due to its complications such as leukostasis, hemorrhage and respiratory failure. To date, little is known about hyperleukocytosis and is considered when patients with acute leukemia present with concomitant symptoms such as respiratory or neurologic symptoms, only then can it be empirically diagnosed. Hyperleukocytosis has a high early mortality due to severe complications, so prompt intervention is quite necessary. Leukapheresis can rapidly remove blasts from peripheral blood circulation to reduce the risk of complications. In recent practice, most clinicians use the ASFA 2019 guidelines for therapeutic apheresis. Unfortunately, there is still no standardized guidelines indicating when to initiate leukapheresis, how often it should be repeated, and when it should be stopped. Some scholars reported that only patients who showed symptoms of leukostasis should receive leukapheresis treatment ${ }^{48}$ and leukapheresis can be repeated multiple times until clinical symptoms regress or the leukocyte count reaches below $100 \times 10^{9} / \mathrm{L}^{27,62}$ We generalized and analyzed previous studies, formulating the indication and therapeutic strategy of leukapheresis in the treatment of hyperleukocytosis (Figure 2). Leukapheresis should be individualized by physician's preference and the contraindication to this modality in the context of underlying cardiovascular disease, hemodynamic 


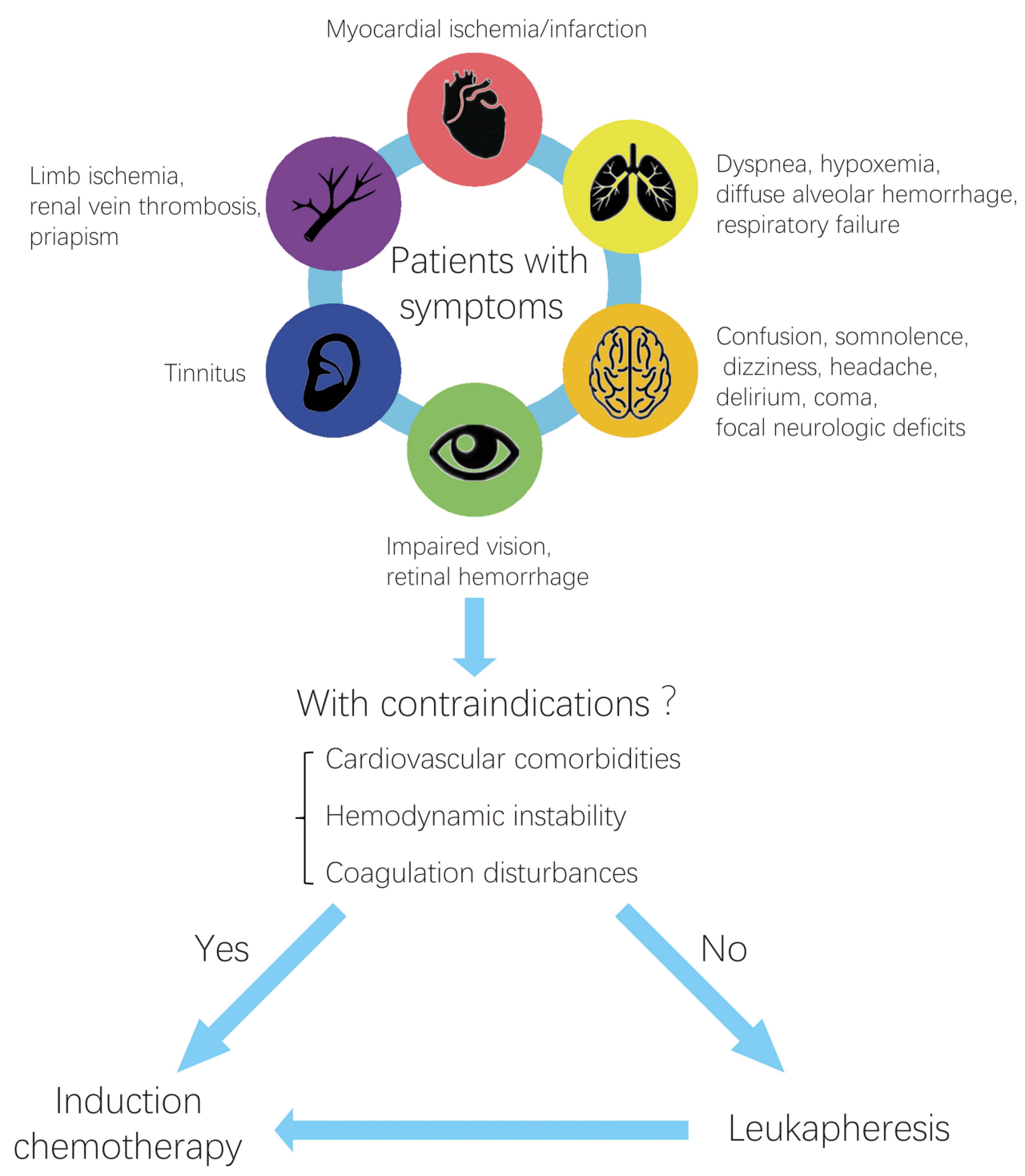

Figure 2 The indication and therapeutic strategy of leukapheresis in the treatment of hyperleukocytosis.

instability (sepsis, shock), active bleeding and coagulopathy such as APL.

In conclusion, leukapheresis can rapidly reduce the leukocyte count, effectively decreases tumor burden, and reduces the incidence of complications. Due to less adverse reactions and good tolerance associated with this therapy, it can be a very effective adjuvant therapy to hyperleukocytosis. What is needed is to grasp the indications of leukapheresis, mastering the operation skill and reducing the incidence of adverse reactions, and at the same time develop new apparatus to achieve more efficient and accurate separation. The pathogenesis of hyperleukocytosis is still unclear. Even though chemotherapy and leukapheresis are useful symptomatic treatments, we must elucidate the pathogenesis and etiological treatments in future.

\section{Ethical Approval}

This article does not contain any studies with human participants or animals performed by any of the authors.

\section{Author Contributions}

All authors made substantial contributions to conception and design, acquisition of data, or analysis and interpretation of data; took part in drafting the article or revising it critically for important intellectual content; agreed to submit to the current journal; gave final approval of the 
version to be published; and agreed to be accountable for all aspects of the work.

\section{Funding}

This work was supported by the Hubei Education Program (grant number JX5B78).

\section{Disclosure}

The authors have no competing interests to report in this work.

\section{References}

1. Okafor C, Ward DM, Mokrzycki MH, Weinstein R, Clark P, Balogun RA. Introduction and overview of therapeutic apheresis. J Clin Apher. 2010;25(5):240-249. doi:10.1002/jca.20247

2. Tanaka T, Yamamoto T, Sawada K, Sacco R. Treatment options for children and adolescents with inflammatory bowel disease: is granulomonocytapheresis an effective alternative to drug therapy? Expert Rev Gastroenterol Hepatol. 2017;11(8):749-758. doi:10.1080/ 17474124.2017.1341309

3. Rowe JM, Lichtman MA. Hyperleukocytosis and leukostasis: common features of childhood chronic myelogenous leukemia. Blood. 1984;63(5):1230-1234. doi:10.1182/blood.V63.5.1230.1230

4. Porcu P, Farag S, Marcucci G, Cataland SR, Kennedy MS, Bissell M. Leukocytoreduction for acute leukemia. Ther Apheresis. 2002;6 (1):15-23. doi:10.1046/j.1526-0968.2002.00402.x

5. Buresh A, Perentesis J, Rimsza L, et al. Hyperleukocytosis complicating lonafarnib treatment in patients with chronic myelomonocytic leukemia. Leukemia. 2005;19(2):308-310. doi:10.1038/sj. leu. 2403569

6. Zuckerman T, Ganzel C, Tallman MS, Rowe JM. How I treat hematologic emergencies in adults with acute leukemia. Blood. 2012;120 (10):1993-2002. doi:10.1182/blood-2012-04-424440

7. Ali AM, Mirrakhimov AE, Abboud CN, Cashen AF. Leukostasis in adult acute hyperleukocytic leukemia: a clinician's digest. Hematol Oncol. 2016;34(2):69-78. doi:10.1002/hon.2292

8. Oberoi S, Lehrnbecher T, Phillips B, et al. Leukapheresis and low-dose chemotherapy do not reduce early mortality in acute myeloid leukemia hyperleukocytosis: a systematic review and meta-analysis. Leuk Res. 2014;38(4):460-468. doi:10.1016/j. leukres.2014.01.004

9. Stoecklein NH, Fischer JC, Niederacher D, Terstappen LW. Challenges for CTC-based liquid biopsies: low CTC frequency and diagnostic leukapheresis as a potential solution. Expert Rev Mol Diagn. 2016;16(2):147-164. doi:10.1586/14737159.2016.1123095

10. Fischer JC, Niederacher D, Topp SA, et al. Diagnostic leukapheresis enables reliable detection of circulating tumor cells of nonmetastatic cancer patients. Proc Natl Acad Sci $U$ S A. 2013;110 (41):16580-16585. doi:10.1073/pnas.1313594110

11. Aqui N, O'Doherty U. Leukocytapheresis for the treatment of hyperleukocytosis secondary to acute leukemia. Hematol Am Soc Hematol Educ Prog. 2014;2014(1):457-460. doi:10.1182/asheducation2014.1.457

12. Tullis JL. Separation and purification of leukocytes and platelets. Blood. 1952;7(9):891-896. doi:10.1182/blood.V7.9.891.891

13. Batchelor WH, D’Hont M, Driscoll S, et al. New principle of closed system centrifugation. Science (New York, NY). 1956;124 (3226):792-797. doi:10.1126/science.124.3226.792

14. Buckner D, Eisel R, Perry S. Blood cell separation in the dog by continuous flow centrifugation. Blood. 1968;31(5):653-672. doi:10.1182/blood.V31.5.653.653
15. Djerassi I, Kim JS, Mitrakul C, Suvansri U, Ciesielka W. Filtration leukapheresis for separation and concentration of transfusable amounts of normal human granulocytes. J Med. 1970;1(6):358-364.

16. Herzig GP, Root RK, Graw RG Jr. Granulocyte collection by continuous-flow filtration leukapheresis. Blood. 1972;39 (4):554-567. doi:10.1182/blood.V39.4.554.554

17. Buckner D, Graw RG Jr, Eisel RJ, Henderson ES, Perry S. Leukapheresis by continuous flow centrifugation (CFC) in patients with chronic myelocytic leukemia (CML). Blood. 1969;33 (2):353-369. doi:10.1182/blood.V33.2.353.353

18. Sethu P, Sin A, Toner M. Microfluidic diffusive filter for apheresis (leukapheresis). Lab Chip. 2006;6(1):83-89. doi:10.1039/B512049G

19. López-Pereira P, Sola Aparicio E, Vicuña Andrés I, et al. Retrospective comparison between COBE SPECTRA and SPECTRA OPTIA apheresis systems for hematopoietic progenitor cells collection for autologous and allogeneic transplantation in a single center. J Clin Apher. 2020;35 (5):453-459. doi:10.1002/jca.21826

20. Duvall D. Therapeutic cytapheresis: too many platelets, too many white blood cells. J Clin Apher. 2011;26(1):47-52. doi:10.1002/ jca.20266

21. Augustsson P, Karlsen JT, Su HW, Bruus H, Voldman J. Iso-acoustic focusing of cells for size-insensitive acousto-mechanical phenotyping. Nat Commun. 2016;7:11556. doi:10.1038/ ncomms 11556

22. Dykes J, Lenshof A, Astrand-Grundstrom IB, Laurell T, Scheding S. Efficient removal of platelets from peripheral blood progenitor cell products using a novel micro-chip based acoustophoretic platform. PLoS One. 2011;6(8):e23074. doi:10.1371/journal.pone.0023074

23. Nam J, Lim H, Kim D, Shin S. Separation of platelets from whole blood using standing surface acoustic waves in a microchannel. Lab Chip. 2011;11(19):3361-3364. doi:10.1039/c1lc20346k

24. Porcu P, Cripe LD, Ng EW, et al. Hyperleukocytic leukemias and leukostasis: a review of pathophysiology, clinical presentation and management. Leuk Lymphoma. 2000;39(1-2):1-18. doi:10.3109/ 10428190009053534

25. Altuntas F, Sari I, Kocyigit I, et al. Comparison of Plateletpheresis on the Fenwal Amicus and Fresenius Com Tec cell separators. Transfusion Med Hemother. 2008;35(5):368-373. doi:10.1159/ 000151351

26. Ruggiero A, Rizzo D, Amato M, Riccardi R. Management of hyperleukocytosis. Curr Treat Options Oncol. 2016;17(2):7. doi:10.1007/s11864-015-0387-8

27. Hölig K, Moog R. Leukocyte depletion by therapeutic leukocytapheresis in patients with leukemia. Transfusion Med Hemother. 2012;39 (4):241-245. doi:10.1159/000341805

28. Ganzel C, Becker J, Mintz PD, Lazarus HM, Rowe JM. Hyperleukocytosis, leukostasis and leukapheresis: practice management. Blood Rev. 2012;26(3):117-122. doi:10.1016/j. blre.2012.01.003

29. Schulz M, Bialleck H, Thorausch K, et al. Unstimulated leukapheresis in patients and donors: comparison of two apheresis systems. Transfusion. 2014;54(6):1622-1629. doi:10.1111/trf.12506

30. Andree KC, Mentink A, Zeune LL, et al. Toward a real liquid biopsy in metastatic breast and prostate cancer: diagnostic LeukApheresis increases CTC yields in a European prospective multicenter study (CTCTrap). Int J Cancer. 2018;143(10):2584-2591. doi:10.1002/ ijc. 31752

31. Padmanabhan A, Connelly-Smith L, Aqui N, et al. Guidelines on the use of therapeutic apheresis in clinical practice - evidence-based approach from the writing committee of the American society for apheresis: the eighth special issue. J Clin Apher. 2019;34 (3):171-354.

32. Eberhardson M, Marits P, Jones M, et al. Treatment of inflammatory bowel disease by chemokine receptor-targeted leukapheresis. Clin immunol. 2013;149(1):73-82. doi:10.1016/j.clim.2013.05.021 
33. Saniabadi AR, Tanaka T, Ohmori $T$, Sawada $K$, Yamamoto $T$, Hanai $\mathrm{H}$. Treating inflammatory bowel disease by adsorptive leucocytapheresis: a desire to treat without drugs. World $J$ Gastroenterol. 2014;20(29):9699-9715. doi:10.3748/wjg.v20.i29.9699

34. Jin Y, Guo S, Cui Q, et al. A hospital based retrospective study of factors influencing therapeutic leukapheresis in patients presenting with hyperleukocytic leukaemia. Sci Rep. 2018;8(1):294. doi:10.1038/s41598-017-17534-4

35. Powell BL, Gregory BW, Evans JK, et al. Leukapheresis induced changes in cell cycle distribution and nucleoside transporters in patients with untreated acute myeloid leukemia. Leukemia. 1991;5 (12): 1037-1042.

36. Bruserud Ø, Liseth K, Stamnesfet S, et al. Hyperleukocytosis and leukocytapheresis in acute leukaemias: experience from a single centre and review of the literature of leukocytapheresis in acute myeloid leukaemia. Transfusion Med. 2013;23(6):397-406. doi:10.1111/ tme. 12067

37. Sung L, Aplenc R, Alonzo TA, Gerbing RB, Gamis AS. Predictors and short-term outcomes of hyperleukocytosis in children with acute myeloid leukemia: a report from the Children's Oncology Group. Haematologica. 2012;97(11):1770-1773. doi:10.3324/ haematol.2012.065490

38. Bojanic I, Mazic S, Rajic L, Jakovljevic G, Stepan J, Cepulic BG. Large volume leukapheresis is efficient and safe even in small children up to $15 \mathrm{~kg}$ body weight. Blood Transfusion = Trasfusione Del Sangue. 2017;15(1):85-92.

39. Galera P, Haynes S, Sulmasy P, et al. Physiological measurements corroborate symptomatic improvement after therapeutic leukapheresis in a pregnant woman with chronic myelogenous leukemia. J Clin Apher. 2016;31(4):393-397. doi:10.1002/jca.21410

40. Staley EM, Simmons SC, Feldman AZ, et al. Management of chronic myeloid leukemia in the setting of pregnancy: when is leukocytapheresis appropriate? A case report and review of the literature. Transfusion. 2018;58(2):456-460. doi:10.1111/trf.14448

41. Yellu M, Pinkard S, Ghose A, Medlin S. CML in pregnancy: a case report using leukapheresis and literature review. Transfusion Apheresis Sci. 2015;53(3):289-292.

42. Giammarco S, Chiusolo P, Piccirillo N, et al. Hyperleukocytosis and leukostasis: management of a medical emergency. Expert Rev Hematol. 2017;10(2):147-154. doi:10.1080/17474086.2017.1270754

43. Allon M. Current management of vascular access. Clin J Am Soc Nephrol. 2007;2(4):786-800. doi:10.2215/CJN.00860207

44. Howard SC, Jones DP, Pui CH. The tumor lysis syndrome. $N$ Engl J Med. 2011;364(19):1844-1854. doi:10.1056/NEJMra0904569

45. Schlenke P, Frohn C, Steinhardt MM, Kirchner H, Kluter H. Clinically relevant hypokalaemia, hypocalcaemia, and loss of hemoglobin and platelets during stem cell apheresis. J Clin Apher. 2000;15(4):230-235. doi:10.1002/1098-1101(2000)15:4<230::AID-JCA3>3.0.CO;2-B

46. Punzel M, Kozlova A, Quade A, Schmidt AH, Smith R. Evolution of MNC and lymphocyte collection settings employing different Spectra Optia $\left({ }^{(}\right)$Leukapheresis systems. Vox Sang. 2017;112(6):586-594. doi:10.1111/vox.12540

47. Sanz MA, Grimwade D, Tallman MS, et al. Management of acute promyelocytic leukemia: recommendations from an expert panel on behalf of the European LeukemiaNet. Blood. 2009;113 (9):1875-1891. doi:10.1182/blood-2008-04-150250

48. Rollig C, How EG. I treat hyperleukocytosis in acute myeloid leukemia. Blood. 2015;125(21):3246-3252. doi:10.1182/blood2014-10-551507
49. Porcu P, Danielson CF, Orazi A, Heerema NA, Gabig TG, McCarthy LJ. Therapeutic leukapheresis in hyperleucocytic leukaemias: lack of correlation between degree of cytoreduction and early mortality rate. Br J Haematol. 1997;98(2):433-436. doi:10.1046/ j.1365-2141.1997.1943011.x

50. Thiébaut A, Thomas X, Belhabri A, Anglaret B, Archimbaud E. Impact of pre-induction therapy leukapheresis on treatment outcome in adult acute myelogenous leukemia presenting with hyperleukocytosis. Ann Hematol. 2000;79(9):501-506. doi:10.1007/s002770000162

51. Giles FJ, Shen Y, Kantarjian HM, et al. Leukapheresis reduces early mortality in patients with acute myeloid leukemia with high white cell counts but does not improve long- term survival. Leuk Lymphoma. 2001;42(1-2):67-73. doi:10.3109/10428190109097677

52. Chang MC, Chen TY, Tang JL, et al. Leukapheresis and cranial irradiation in patients with hyperleukocytic acute myeloid leukemia: no impact on early mortality and intracranial hemorrhage. $\mathrm{Am}$ J Hematol. 2007;82(11):976-980. doi:10.1002/ajh.20939

53. Choi MH, Choe YH, Park Y, et al. The effect of therapeutic leukapheresis on early complications and outcomes in patients with acute leukemia and hyperleukocytosis: a propensity score-matched study. Transfusion. 2018;58(1):208-216. doi:10.1111/trf.14329

54. Nan X, Qin Q, Gentille C, et al. Leukapheresis reduces 4-week mortality in acute myeloid leukemia patients with hyperleukocytosis - a retrospective study from a tertiary center. Leuk Lymphoma. 2017;58(9):1-11. doi:10.1080/10428194.2016.1277386

55. Wong GC. Hyperleukocytosis in acute myeloid leukemia patients is associated with high 30-day mortality which is not improved with leukapheresis. Ann Hematol. 2015;94(12):2067-2068. doi:10.1007/ s00277-015-2472-2

56. Bug G, Anargyrou K, Tonn T, et al. Impact of leukapheresis on early death rate in adult acute myeloid leukemia presenting with hyperleukocytosis. Transfusion. 2007;47(10):1843-1850. doi:10.1111/j.1537-2995.2007.01406.x

57. Pastore F, Pastore A, Wittmann G, Hiddemann W, Spiekermann K. The role of therapeutic leukapheresis in hyperleukocytotic AML. PLoS One. 2014;9(4):e95062. doi:10.1371/journal.pone.0095062

58. Stahl M, Shallis RM, Wei W, et al. Management of hyperleukocytosis and impact of leukapheresis among patients with acute myeloid leukemia (AML) on short- and long-term clinical outcomes: a large, retrospective, multicenter, international study. Leukemia. 2020;34 (12):3149-3160. doi:10.1038/s41375-020-0783-3

59. Shallis RM, Stahl M, Bewersdorf JP, Hendrickson JE, Zeidan AM. Leukocytapheresis for patients with acute myeloid leukemia presenting with hyperleukocytosis and leukostasis: a contemporary appraisal of outcomes and benefits. Expert Rev Hematol. 2020;13(5):489-499. doi:10.1080/17474086.2020.1751609

60. Sietsma H, Kamps WA, Dontje B, et al. Leukemia-induced bone marrow depression: effects of gangliosides on erythroid cell production. Int $J$ Cancer. 1999;82(1):92-97. doi:10.1002/(SICI) 1097-0215(19990702)82:1<92::AID-IJC16>3.0.CO;2-J

61. Shahrabi S, Behzad MM, Jaseb K, Saki N. Thrombocytopenia in leukemia: pathogenesis and prognosis. Histol Histopathol. 2018;33 (9):895-908.

62. Schwartz J, Winters JL, Padmanabhan A, et al. Guidelines on the use of therapeutic apheresis in clinical practice-evidence-based approach from the Writing Committee of the American Society for Apheresis: the sixth special issue. J Clin Apher. 2013;28(3):145-284. doi: $10.1002 /$ jca.21276 


\section{Publish your work in this journal}

The International Journal of General Medicine is an international, peer-reviewed open-access journal that focuses on general and internal medicine, pathogenesis, epidemiology, diagnosis, monitoring and treatment protocols. The journal is characterized by the rapid reporting of reviews, original research and clinical studies

across all disease areas. The manuscript management system is completely online and includes a very quick and fair peer-review system, which is all easy to use. Visit http://www.dovepress.com/ testimonials.php to read real quotes from published authors.

Submit your manuscript here: https://www.dovepress.com/international-journal-of-general-medicine-journal 